\title{
How to represent adaptation in eLearning with IMS Learning Design
}

Citation for published version (APA):

Burgos, D., Tattersall, C., \& Koper, R. (2008). How to represent adaptation in eLearning with IMS Learning Design. Interactive LearnIng Environments, 15(2), 161-170. https://doi.org/10.1080/10494820701343736

DOI:

$10.1080 / 10494820701343736$

Document status and date:

Published: 31/05/2008

Document Version:

Peer reviewed version

Document license:

CC BY-NC-ND

Please check the document version of this publication:

- A submitted manuscript is the version of the article upon submission and before peer-review. There can be important differences between the submitted version and the official published version of record. People interested in the research are advised to contact the author for the final version of the publication, or visit the DOI to the publisher's website.

- The final author version and the galley proof are versions of the publication after peer review.

- The final published version features the final layout of the paper including the volume, issue and page numbers.

Link to publication

\section{General rights}

Copyright and moral rights for the publications made accessible in the public portal are retained by the authors and/or other copyright owners and it is a condition of accessing publications that users recognise and abide by the legal requirements associated with these rights.

- Users may download and print one copy of any publication from the public portal for the purpose of private study or research.

- You may not further distribute the material or use it for any profit-making activity or commercial gain

- You may freely distribute the URL identifying the publication in the public portal.

If the publication is distributed under the terms of Article 25fa of the Dutch Copyright Act, indicated by the "Taverne" license above, please follow below link for the End User Agreement:

https://www.ou.nl/taverne-agreement

Take down policy

If you believe that this document breaches copyright please contact us at:

pure-support@ou.nl

providing details and we will investigate your claim.

Downloaded from https://research.ou.nl/ on date: 26 Apr. 2023 


\title{
How to represent adaptation in eLearning with IMS Learning Design
}

\author{
Daniel Burgos, Colin Tattersall and Rob Koper \\ Educational Technology Expertise Centre (OTEC) \\ The Open University of The Netherlands \\ Valkenburgerweg 177, 6419 AT Heerlen, The Netherlands \\ Email: \{dbu,cta,rkp\}@ou.nl, Tel: +31455762464, Fax: +31455762802
}

\begin{abstract}
Adaptation in eLearning has been an important research topic for the last few decades in computerbased education. In adaptivity the behaviour of the user triggers some actions in the system that guides the learning process. In adaptability, the user makes changes and takes decisions. Progressing from Computer Based Training and Adaptive Hypermedia Systems, adaptation in eLearning today involves new technologies and ways of expression. In this context, IMS Learning Design (IMS LD) is an eLearning specification that allows for modelling learning experiences including adaptation and personalized learning. IMS LD fulfils many of the requirements for realizing adaptive and adaptable units of learning/courses.

In this paper we review several approaches to adaptation and eLearning. In addition. we give an overview of adaptation and its main characteristics. In the second section we identify how adaptive features and elements can be modelled in IMS LD, detailing a number of example units of learning which illustrate different forms of adaptation. In the final section we discuss issues in attaining the right balance between effort invested and results acquired while modelling IMS LD adaptive Units of Learning.
\end{abstract}

\section{Keywords}

Adaptation, adaptivity, adaptability, personalized learning, IMS Learning Design

\section{Introduction. A focus on adaptation}

There are many definitions of adaptation in eLearning systems (Ahmad, Basir et al., 2004; Henze and Nejdl, 2004; Chen and Magoulas, 2005; Cristea, 2005). The two main terms usually involved are adaptivity and adaptability. In short, adaptavity is the ability to modify eLearning lessons using different parameters and a set of pre-defined rules. In contrast, adaptability is the possibility for learners to personalize an eLearning lesson by themselves. These terms reflect a series of possibilities, from those centered on the machine (adaptivity) to those centered on the user (adaptability). However, adaptivity and adaptability are closely related (Klann, 2003), and are often both used for personalized learning. From now onwards, we will use all these terms (adaptivity, adaptability, adaptation and personalized learning) to refer to the eLearning process on adaptation.

From the user interface through the eLearning resources to the learning process there are many aspects to take into consideration for effective adaptation. From the early eighties, where Computer Based Training was used to fully control the flow of a learning process (Tennyson, 1980; Tennyson, 1981), to the concept of Adaptive Guidance, which provides rich information and a diagnosis to help the learner to take effective decisions about his own learning (Bell and Kozlowski, 2002), there is a wide collection of approaches to adaptation in eLearning. For instance, to incorporate the tutor as a key factor in the adaptation process (Van 
Rosmalen, Vogten et al., 2006), or to build a blended system strongly supported by AI agents (Wasson, 1997). All are based on the proposal of personalized learning adaptation to the context of each student in order to stimulate his learning process and to encourage his involvement in this process (Fredericksen, Pickett et al., 2000; He, Kinshuk et al., 2002; Burgos and Ruiz-Mezcua, 2003) These approaches also hold that the best learning performance comes from personalized instruction (Towle and Halm, 2005). This does not necessarily imply that a user/student should keep full control over his training, because this would mean that 1 ) the student knows what is the best for him along a learning script; 2) the student is aware, knows and controls all the contributions that he can make to his own process; and 3) the student is able to carry out the right decision when all this information is collected (Snow, 1980).

We define adaptation in eLearning as a method to create a learning experience for the student, but also for the tutor, based on the configuration of a set of elements in a specific period aiming to increase of the performance of pre-defined criteria (Van Rosmalen, Vogten et al., 2006). These criteria could be i.e. educational, economic, time-based or user satisfaction-based. Elements to modify/adapt could be based on content, time, order, assessment, interface and so on.

\section{Who makes the adaptation?}

Usually, adaptation is focused on the student. Adaptation involving tutors is clearly also possible, although it could be more time and resource consuming because the teacher should provide a personal or group guidance instead of giving collective lectures or in addition to them. A third element in the list of adaptation-makers is the set of rules that provides adaptation taking different inputs from the different stakeholders. Taking into account these three factors (user, teacher and set of rules) instead of only one (user) a full and richer adaptation system can be setup. The final goal for all of them is to provide the best fit to personalized learning objectives. Furthermore, we count up to four inputs in a balanced formula for adaptation: a) the user, when some information is taken from his behavior and performance and when the cognitive load is reduced to the minimum or even at all (Tennyson, 1980; Tennyson, 1981; Klann, 2003; De Bra, Stash et al., 2005); b) the user, when he contributes with his/her own personal decision and he takes over the next step to take along the learning path (Bell and Kozlowski, 2002); c) the teacher, when he also contributes with his/her personal decision and he evaluates the personal situation of the user related to the full learning experience (Van Rosmalen, Vogten et al., 2006); and d) the set of pre-defined rules made by the learning designer/author (usually, the same teacher) (Wasson, 1997); this kind of adaptation engine is usually expressed in the way of AI agents and nested conditions. The inputs a) and b) provide some personal needs and drives to learn; the inputs c) and d) take care of the didactical quality and of the learning efficiency.

Finally, when we refer to the user, this could also imply a user-group, where a set of objectives, activities and processes is setup for a whole.

\section{Types of adaptation}

A combination of the following proposals on adaptation could support the performance of every role in an eLearning process (Cronbach, 1957; He, Kinshuk et al., 2002).

Traditionally, three types of adaptation have been proposed:

1. Interface-based (also called adaptive navigation and related to usability and adaptability) where elements and options of the interface, are positioned on the screen and their properties are defined (color, size, shadow, etc) (Ahmad, Basir et al., 2004); this is closely related to general customization and supporting people with special needs which influence personalization, such as color blindness or poor hearing, for instance (Chin, 2001).

2. Learning flow-based, where the learning process is dynamically adapted to sequence the contents of the course in different ways. The learning path is dynamic and personalized for every user, but even also for 
every time that the course is started (also called run or instance), so that the user can take a different itinerary depending on his performance.

3. Content-based, where resources and activities dynamically change their actual content, as in Adaptive and Intelligent Web-Based Educational Systems based on adaptive presentation (Brusilovsky and Miller, 2001; De Bra, Aroyo et al., 2004). For instance, the information inside a learning activity can be classified in three levels of depth, and every level is shown based on a number of factors.

The first block of adaptation types are the base for the following ones. Additional kinds of adaptation are (Brusilovsky and Paylo, 2003):

4. Interactive problem solving support, which guides the user on the next step to take in order to get the right solution to a problem. The guidance could come from an online or offline tutor or from a predefined set of rules.

5. Adaptive information filtering, taking care of appropriate information retrieval that provides only relevant and categorized outputs to the user (Baeza-Yates and Ribeiro-Nieto, 1999). Although this type provides adaptive information, it could be considered as an external facility linked to a learning activity and not as a real part of that learning activity itself.

6. Adaptive user grouping, that allows ad hoc creation of groups of users and collaborative support on carrying out specific tasks. For instance, as a result of a pool of questions, two groups with beginners and advanced users are made.

We extend the classification further with:

7. Adaptive evaluation, where the evaluation model, the actual content and the running of a test can change depending on the performance of the student and the guidance of the tutor (Van Rosmalen, Vogten et al., 2006).

8. Changes on-the-fly, the possibility to modify/adapt a course on-the-fly by a tutor or the author of the course in run-time (Van
Rosmalen and Boticario, 2005), moving beyond the previous types which are set-up and defined in design-time (Merceron and Yacef, 2003; Romero, Ventura et al., 2003).

In a literature study, we identify eight different kinds of adaptation being carried out in eLearning systems (Specht and Burgos, 2006). All of them use various inputs provided during the learning process and aim to tune the activities and actions of the learner to get the best learning experience as possible (Butz, Olivier et al., 2003). A wide and consistent set of rules of dependencies among users, methods and learning objects is needed to describe these eight types of adaptation, and moreover their possible combinations (Karampiperis and Sampson, 2004).

\section{IMS Learning Design and adaptation}

IMS LD (IMSLD, 2003) provides a modelling language able to design executable Units of Learning (UoLs) (Koper and Olivier, 2004; Burgos and Koper, 2005; Koper and Tattersall, 2005). There are two main approaches to create adaptive UoLs: First, an initial analysis by Towle and Halm (2005) sees the adaptation fully modelled inside a Unit of Learning, and describes four areas in IMS LD where some kind of adaptation could take place: environment, method, roles and activities. Second, Van Rosmalen and Boticario (2005) examine the external adaptation of a UoL, making modifications to both the internal elements of the UoL and the playing layer through which the UoL is delivered (player).

We now examine how IMS LD can be used to represent each of the eight types of adaptation aforementioned.

\subsection{Interface based}

Interface adaptation is based on menu options, navigation facilities and visualization facilities. This issue relates to the user interface provided with IMS LD players such as the player included with CopperCore (Vogten and Martens, 2005), the Reload Player (Reload, 2004) and Sled (The Open University, 2005). The current generation of 
these tools do not provide facilities to allow interface adaptation in run-time, although Sled can be customized during the set-up using stylesheets. Current LD IMS players cannot change the size and position of their panels or working areas, the definition of their windows or any other navigation facility. These players cannot change basic features, like font-size, fontcolor, font-type or alignement, either. There is a distinction between the external wrapper of the Unit of Learning (player) and the actual Unit of Learning itself with real content and learning activities. The player is the tool that allows for interpreting and viewing the Unit of Learning. Although interface adaptation cannot be carried out with the current players, some kind is possible inside the unit of learning, if we use two resources: DIV layers and environments. We can work with DIV layers that can be shown and hidden in run-time by any of the main participants in the learning process (user, teacher, set of rules). Inside a DIV layer we can define different options and/or look and feels of the same content, meaning a de facto interface based adaptation. In the same line, we can use several environments to provide different setups (contents, approaches, views) related to the same unit of learning, leading to a final personalized interface. Although neither of these two solutions (DIV layers and environments) is based on the external wrapper/player they can provide another view to interface adaptation.

\section{2 . Learning flow based}

The description of an adaptive learning flow is mainly based on four out of the five different available elements of IMS LD at Level B (Burgos and Koper, 2005; Koper and Burgos, 2005): properties, calculations, global elements and conditions. In addition, monitoring services can be added to track users' behaviour and allow the teacher to adapt the flow dynamically. An example of these features is provided by Learning to Listen to Jazz (all the examples can be found at (LN4LD, 2005)). A student can learn something about four different Jazz styles in a sequential way, and he can choose between a thematic itinerary and a historical itinerary, following different milestones in the course. An additional example is GeoQuiz 3 where the activities are defined by the performance of a student after answering an evaluation form. Depending on the final score and the related level acquired, one or another activity is shown. A final example is Cándidas II showing full learner control by the student, who directly selects which is the best method to study a lesson among four different options.

\section{3 . Content based}

The content of an activity needs a resource linked to the element Activity Description. Although this link cannot be changed at run-time, three other elements can be modified dynamically:

- the content inside an XHTML resource, defining classes and DIV layers that can be hidden and shown based on certain parameters;

- the content of pre-defined properties/variables, that can be replaced with other content typed-in on the fly;

- the content of an activity can be adapted switching showing or hiding one of several linked environments.

Two examples of the use of environments are Learning Activities with Conditions, where a student decides the granularity level that he wants and From Lesson Plan to LD Level B, where again a student takes control and switches on and off the audio support of the UoL. Finally, the aforementioned Learning to Listen to Jazz provides contents linked to several Activity Descriptions and related environments, progressbased.

An additional way of content-based adaptation is the modification of contents linked to fixed resources and based on external tools. For instance, a resource linked to a wiki service hosted outside an IMS LD UoL could adapt its content dynamically, based on users', tutors' or authors' contributions.

\subsection{Interactive problem solving support}


This kind of adaptation could be considered as an extension of learning flow based, with the appropriate definition of properties and conditions modelling the itinerary, and the incorporation of a monitoring service allowing the tracking of the learning process of the student, making ad hoc remarks and changing the process as needed. These changes can be carried out 1 ) by modifying specific arguments by the tutor, 2) by the execution of specific design-time rules, or 3 ) by a combination of both mechanisms. An example is What is Greatness where the tutor moderates the contributions of a group of students on an open question, providing access to the next step when the tutor thinks that the current one is finished. A further example is Free Style Assessment where a tutor and a student carry out a commented open evaluation of an assessment. The tutor is entitled to close and block every step and to provide contextual feedback.

\section{5 . Adaptive information filtering}

IMS LD is not designed to provide adaptive information retrieval. Some rudimentary facilities are available through the index-search service. More practically, IMS LD could point out to an external searching service providing the container for the run of this application and also for the visualization of the results.

\section{6 . Adaptive user grouping}

User management has two approaches, one based on role creation, where the users are assigned to, and one based on the creation of the users itself. Using the management system provided by several tools and engines - Coppercore, Reload, CopperAuthor (Van der Vegt, 2005) - once the UoL is published, the administrator (maybe the teacher himself) can add and delete users and assign them to a specific run of that UoL. This means a de facto group (Burgos, 2004). However, the dynamic creation of roles after the publishing process is not currently possible. Once a definition of roles or stakeholders is available, and a run of a UoL is defined, specific users can be added to, or removed from, any of these groups and these users can play the run. Some representational facilities are available in IMS LD to support creation of groups (min-persons and max-persons) and although assignment of users to groups can be achieved, fully automatic on-the-fly creation of groups may require additional representational devices.

\subsection{Adaptive evaluation}

Taking the performance of a student in a Unit of Learning as input, a full set of parameters can be stored in local properties to be used in the adaptation of formative or summative evaluations. As we have already explained related to Geo Quiz 3 , certain actions and answers of a user can be allocated into variables pre-defined in design-time and they can also be interpreted in run-time following a set of rules. In this way, both the evaluation system and the content itself, and even the interpretation of the results, can change for each user. An example is Quo Builder 2 where a questionnaire can be fully set-up with questions, answers, thresholds and feedback being defined in run-time. Again, the main obstacle to overcome is the run-time modification of the skeleton itself, such as the ordering, grouping and numbering of questions and answers; something not possible so far with the current state of tooling. However we can define a wide set of questions that can also be hidden and shown on demand, providing a topdown 'simulation' of adaptive extensibility.

\subsection{Changes on-the-fly}

Every UoL has three clearly different steps in its own life-cycle: design-time, publishing-time and run-time (Koper and Tattersall, 2005). With the current tools, once a UoL is published it is not possible to change structure, method or definition of basic parameters (such as conditions or properties, for instance). Of course, if a UoL is so designed, a tutor is able to change the way a student perceives the course and the flow: 1) tutors can update the content, based on predefined content or on new contributions; and 2) tutor can also influence the learning itinerary, uploading files, showing and hiding content elements and structure elements, etc. This means 
that a tutor is able to change things on the run, as long as he had previously defined that possibility in design-time. This solution comes with a high expense on implementation and support, though. An example is the already mentioned Quo Builder 2 where a tutor makes the set-up and initialization of an evaluation form within run-time, that is subsequently filled by students.

\section{Conclusion}

Adaptation is a quite complex process taking into account several stakeholders and inputs: User, teacher and set of rules. Also the right balance between the cognitive load of users and teachers and the non-voluntary actions that can be taken as inputs in the set of rules defined inside an engine should be composed. IMS Learning Design seems a promising expressive language that allows for several types of adaptation. We can use the elements available at Level B - such as conditions, properties, calculations, global elements and monitoring services- to model and run rich and adaptive Units of Learning.

The possibilities for adaptation supported by IMS LD are diverse. From the eight types of adaptation described we identify three levels of support: a) Learning flow, content, evaluation and interactive problem solving support are well supported; b) User grouping, interface adaptation, adaptive evaluation and full modification of a course onthe-fly are partially supported; c) Last, as some pending issues with no support at all are dynamic modification of learning structure and method in run-time, and adaptive information filtering and retrieval. Some of this lack of support leans on the current state of tooling, and not on the specification itself, though.

Nevertheless, with several types of adaptation, like content and information retrieval, also it is possible to provide specific support on adaptation, i.e. linking a learning activity to an external tool that provides a related service and keeping IMS $\mathrm{LD}$ as a container for external adaptation. To this extent, adaptation comes from outside IMS LD although the learning design acts as an integrator. In conclusion, with the appropriate support, IMS LD can build adaptation and rather flexible learning experiences for every stakeholder.

\section{Acknowledgements}

This paper is partially supported by the European Projects ProLearn and TENCompetence.

\section{References}

Ahmad, A., O. Basir and K. Hassanein (2004). Adaptive user interfaces for intelligent $e$ Learning: issues and trends. The Fourth International Conference on Electronic Business, ICEB2004, Beijing.

Baeza-Yates, R. and B. Ribeiro-Nieto (1999). Modern Information Retrieval. Boston, MA, USA, Addison-Wesley.

Bell, B. and S. Kozlowski (2002). Adaptive guidance: Enhancing self-regulation, knowledge, and performance in technology-based training. Personnel Psychology 55(2): 267-306.

Brusilovsky, P. and P. Miller (2001). Course Delivery Systems for the Virtual University. Access to Knowledge: New Information Technologies and the Emergence of the Virtual University. Tschang F.T. and T. Della Senta. Amsterdam, Elsevier Science and International Association of Universities: 167-206.

Brusilovsky, P. and C. Paylo (2003). Adaptive and Intelligent Web-based Educational Systems. International Journal of Artificial Intelligence in Education 13: 156-169.

Burgos, D. (2004). Step by step. How to install CopperCore, how to publish and run a UoL, The Open University of the Netherlands. Retrieved February 21st from http://hdl.handle.net/1820/327.

Burgos, D. and R. Koper (2005). Practical pedagogical uses of IMS Learning Design's Level $B$. SIGOSSEE 2005 Conference, Heerlen, the Netherlands.

Burgos, D. and B. Ruiz-Mezcua (2003). Building an interactive training methodology to develop 
multimedia elearning software. International Conference On Education, Information Systems, Technologies and Applications EISTA 2003, Orlando, Florida, USA.

Butz, M. V., S. Olivier and P. Gérard (2003). Anticipatory Behavior in Adaptive Learning Systems : Foundations, Theories, and Systems. Berlin, Springer Verlag.

Chen, S. Y. and G. D. Magoulas (2005). Adaptable and Adaptive Hypermedia Systems. Hershey, PA, IRM Press.

Chin, D. (2001). Empirical Evaluation of User Models and User-Adapted Systems. User Modeling and User-Adapted Interaction 11: 181194.

Cristea, A. (2005). Authoring of Adaptive Hypermedia. Educational Technology \& Society 8(3): 6-8.

Cronbach, L. J. (1957). The two disciplines of scientific psychology. American Psychologist 12: 671-684.

De Bra, P., L. Aroyo and A. Cristea (2004). Adaptive Web-based Educational Hypermedia. Web Dynamics, Adaptive to Change in Content, Size, Topology and Use. M. Levene and A. Poulovassilis, Springer: 387-410.

De Bra, P., N. Stash and D. Smits (2005). Creating Adaptive Web-Based Applications. 10th International Conference on User Modeling, Edinburgh, Scotland.

Fredericksen, E., A. Pickett, P. Shea and W. Pelz (2000). Student satisfaction and perceived learning with on-line courses: Principles and examples from the SUNY Learning Network. Journal of Asynchronous Learning Networks 4(2).

He, S., Kinshuk, Hong H. and Patel A. (2002). Granular Approach to Adaptivity in Problembased Learning Environment. ICALT.
Henze, N. and W. Nejdl (2004). A logical characterization of adaptive educational hypermedia. New Review in Hypermedia and Multimedia, 10(1).

IMSLD (2003). IMS Learning Design Specification. Boston, The IMS Global Learning Consortium. Retrieved February 27th from http://www.imsglobal.org/learningdesign/index.cf $\mathrm{m}$.

Karampiperis, P. and D. Sampson (2004).

Adaptive learning object selection in intelligent learning systems. Journal of Interactive Learning Research 15(4): 389-408.

Klann, M. (2003). The EUD-Net's Roadmap to End-User Development. Workshop on End User Development at ACM CHI 2003 Conference, Fort Lauderdale, USA.

Koper, R. and D. Burgos (2005). Developing advanced units of learning using IMS Learning Design level B. International Journal on Advanced Technology for Learning 2(3).

Koper, R. and B. Olivier (2004). Representing the Learning Design of Units of Learning. Educational Technology \& Society 7(3): 97-111.

Koper, R. and C. Tattersall, Eds. (2005). Learning Design - A Handbook on Modelling and Delivering Networked Education and Training. Heidelberg, Springer Verlag.

LN4LD (2005). Units of Learning developed by several authors at Learning Network for Learning Design of The Open University of The Netherlands. Retrieved March 6th from http://moodle.learningnetworks.org/course/view.p hp?id=20.

Merceron, A. and K. Yacef (2003). A Web-based tutoring tool with mining facilities to improve learning and teaching. AI-Ed'2003, IOS Press.

Reload (2004). The Reload Project, The University of Bolton, The University of 
Strathclyde and JISC. Retrieved February 9th from http://www.reload.ac.uk/editor.html.

Romero, C., S. Ventura, P. D. De Bra and C. D. Castro (2003). Discovering prediction rules in AHA! courses. 9th International User Modeling Conference.

Snow, R. (1980). Aptitude, learner control and adaptive instruction. Educational Pshychologist 15(13): 151-158.

Specht, M. and D. Burgos (2006). Implementing Adaptive Educational Methods with IMS Learning Design. Adaptive Hypermedia 2006

[www.ah2006.org], Dublin (Ireland).

Tennyson, R. D. (1980). Instructional control strategies and content structure as design vairables in concept acquisition using computer-based instruction. Journal of Educational Psychology 72: 525-532.

Tennyson, R. D. (1981). Use of adaptive information for advisement in learning concepts and rules using computer assisted instruction. American Educational Research Journal 18: 425438.

The Open University (2005). The Sled player. Retrieved February 9th from http://sled.open.ac.uk.

Towle, B. and M. Halm (2005). Designing adaptive learning environments with Learning Design. Learning Design: A Handbook on Modeling and Delivering Networked Education and Training. R. Koper and C. Tattersall. Heidelberg, Germany, Springer Verlag.

Van der Vegt, W. (2005). CopperAuthor. heerlen, Open University of the Netherlands. Retrieved February 23rd from www.copperauthor.org.

Van Rosmalen, P. and J. Boticario (2005). Using Learning Design to support design- and runtime adaptation. Learning Design: A Handbook on Modeling and Delivering Networked Education and Training. R. Koper and C. Tattersall. Heidelberg, Germany, Springer Verlag.

Van Rosmalen, P., H. Vogten, R. Van Es, P. Van, H.,, P. Poelmans and R. Koper (2006). Authoring a full life cycle model in standards-based, adaptive e-learning. Educational Technology \& Society 9(1): 72-83.

Vogten, H. and H. Martens (2005). CopperCore. Heerlen, the Netherlands, Open University of the Netherlands. Retrieved February 9th from www.coppercore.org.

Wasson, B. (1997). Advanced educational technologies: The learning environment. Computers in Human Behavior 13(4): 571-594. 